\title{
A interdisciplinaridade da Ciência da Informação e suas contribuições no estudo do compartilhamento de dados governamentais na internet
}

\author{
Fábio Mosso Moreira \\ Mestre; Universidade Estadual Paulista, Marília, SP, Brasil; \\ fabiomoreira@tupa.unesp.br \\ Marta Lígia Pomim Valentim \\ Doutora; Universidade Estadual Paulista, Marília, SP, Brasil; \\ valentim@valentim.pro.br \\ Ricardo César Gonçalves Sant'Ana \\ Doutor; Universidade Estadual Paulista, Marília, SP, Brasil; \\ ricardosantana@marilia.unesp.br
}

\begin{abstract}
Resumo: A internet pode ser considerada uma importante alternativa para viabilizar maior interação entre a administração pública e a sociedade, como, por exemplo, no compartilhamento de bases de dados governamentais. Esse fluxo informacional envolve questões específicas que são alvo de estudos na Ciência da Informação, que apresenta característica interdisciplinar em função da complexidade de seu objeto, da utilização de teorias e metodologias oriundas de outras áreas, e da diversidade de seu corpo científico. A pesquisa objetivou identificar os campos do conhecimento que apresentam interação interdisciplinar com a Ciência da Informação, evidenciar quais deles podem contribuir para o estudo do compartilhamento de dados governamentais na internet e relacionar disciplinas da área com a análise dos aspectos presentes nesse fluxo informacional. Aplicou-se o método Análise de Conteúdo, a partir da coleta de dados nos portais oficiais da Universidade de São Paulo, campus de Ribeirão Preto, Universidade Federal de São Carlos e Universidade Federal de Santa Catarina, a fim de identificar a estrutura curricular dos cursos de graduação com enfoque na área de Ciência da Informação no Brasil e analisar seus respectivos planos de ensino. Os resultados indicam quais áreas do conhecimento são interdisciplinares à Ciência da Informação e que podem contribuir com o estudo dos aspectos envolvidos no processo de compartilhamento de dados governamentais na internet. Além disso, destaca, também, quais são as disciplinas que compõem a estrutura dos cursos analisados e que, efetivamente, podem contribuir para o estudo desse fluxo informacional.
\end{abstract}

Palavras-chave: Interdisciplinaridade. Ciência da Informação. Compartilhamento de dados. Dados governamentais. Fluxos de informação. 


\section{Introdução}

A internet pode ser considerada uma alternativa para viabilizar o compartilhamento de dados de um modo dialógico, desde que as ações observem requisitos que propiciem adaptar os dados e suas formas de acesso, aos veículos, públicos e contextos. Neste sentido, Lara e Conti (2003) debatem sobre o compartilhamento de dados, propondo o abandono da unidirecionalidade emissor-receptor, a fim de contemplar o usuário em uma dimensão mais ampla, incluindo-o como participante ativo dos processos informacionais.

No âmbito governamental, Sant'Ana (2009) destaca que a internet pode proporcionar meios para viabilizar maior interação entre a administração pública e os indivíduos e grupos da sociedade. Isso é válido tanto para os cidadãos que buscam informações governamentais, inserindo-os, assim, nos processos de participação democrática, quanto para o governo que deve fornecer mecanismos mais eficientes e transparentes de acesso aos serviços públicos de disponibilização de dados.

Por outro lado, a disponibilização de dados governamentais não é realizada de modo centralizado, ou seja, cada órgão do governo elabora, em seus websites oficiais, mecanismos para o atendimento dos aspectos legais referentes às iniciativas de transparência. Isso resulta em características heterogêneas de recursos informacionais e de conjuntos de dados pulverizados em diferentes ambientes informacionais (SANT'ANA; RODRIGUES, 2013).

Esses aspectos indicam a necessidade de que haja estudos para amenizar os problemas envolvidos no fluxo informacional que envolve o compartilhamento de dados governamentais na internet, processo este que pode ter suas questões fundamentadas pela Ciência da Informação, área que tem como objeto de estudo a informação. Tal elemento, compreendido como um conjunto finito de dados dotados de semântica, adquire significado quando vinculado ao contexto do agente que a interpreta, em meio a fatores como tempo, forma de transmissão e suporte utilizado (SANTOS; SANT'ANA, 2002). 
Para que haja apropriação de uma informação, primeiramente, é necessário obter um conjunto de dados que, após processados cognitivamente por um indivíduo, podem atender a uma necessidade informacional. Nessa perspectiva, um dado pode ser descrito como elemento básico formado por signos e que não contém, intrinsicamente, um componente semântico, mas somente elementos sintáticos (SANTOS; SANT'ANA, 2002). Ou seja, o dado pode ser considerado uma unidade de conteúdo estruturada pela tríade [entidade, atributo e valor] e inserida em determinado contexto vinculado ao utilizador (SANTOS; SANT'ANA, 2013). Considera-se, para esta pesquisa, que o dado também é objeto de estudo da Ciência da Informação que, por sua vez, deve ultrapassar a fronteira da informação interpretada, a fim de atingir o nível rígido dos dados (MOREIRA; VALENTIM; SANT’ANA, 2016).

Para Borko (1968), a Ciência da Informação é uma ciência interdisciplinar que investiga as propriedades e os comportamentos da informação, as forças e as técnicas que governam os fluxos e os usos da informação, tanto manual quanto mecânica de processamento da informação, visando sua armazenagem, recuperação e disseminação. Esta apresenta característica interdisciplinar devido à complexidade de seu objeto (a informação), à utilização de teorias e metodologias oriundas de outras áreas, e à diversidade de origem de formação e atuação de seu corpo científico (BICALHO; OLIVEIRA, 2011).

Segundo Saracevic (1995), para entender a informação, suas manifestações e seus efeitos, o comportamento informacional humano e o processo de torná-la acessível a partir de estoques de conhecimento, deve-se considerar a aplicação de soluções tecnológicas que não podem ser resolvidas em uma única área do conhecimento. Nessa perspectiva, o autor ressalta que a Ciência da Informação não é o único campo destinado ao problema da informação, por isso apresenta tantas intersecções com outras áreas, havendo uma sinergia investigativa no estudo dos problemas de pesquisa.

Nesse sentido, levanta-se a questão sobre quais os campos do conhecimento que a Ciência da Informação tem relações interdisciplinares e que 
podem, efetivamente, contribuir para o estudo do compartilhamento de dados governamentais na internet, bem como quais as disciplinas da área fornecem subsídios teóricos e práticos para avaliar os aspectos presentes nesse fluxo informacional.

Para tanto, a pesquisa objetivou identificar os campos do conhecimento que têm interação interdisciplinar com a Ciência da Informação, evidenciar quais deles podem contribuir para o estudo do compartilhamento de dados governamentais na internet, e relacionar disciplinas da área com a análise dos aspectos presentes neste fluxo informacional.

\section{Compartilhamento de dados governamentais na internet}

O uso da internet como tecnologia de compartilhamento de dados pode proporcionar alternativas para a ampliação da transparência pública e participação democrática do cidadão, desde que condicionada aos processos de governança e de cidadania. Para Sant'Ana (2009), a utilização dessa tecnologia pelo governo, no que tange ao gerenciamento de dados, pode ser dividida em uso interno, auxiliando os processos internos da gestão da coisa pública, e uso externo, facilitando a relação entre a organização pública e as entidades externas.

A responsabilidade das administrações públicas em disponibilizar dados e informações sobre suas ações ganhou visibilidade com a promulgação da Lei Federal no 12.527/2011, denominada Lei de Acesso à Informação (LAI). Essa lei adicionou novas obrigações às instituições públicas, reforçando o dever do Estado em garantir o direito de acesso à informação de maneira transparente, clara e em linguagem de fácil compreensão, dispondo, também, sobre a obrigação da divulgação de informações em sites oficiais na rede internet (BRASIL, 2011).

Sant'Ana (2009) ressalta a importância dos governos em disponibilizar informações sobre suas ações, fornecendo, principalmente, dados sobre: planos e programas governamentais; orçamentos, arrecadação e fontes de receita; 
licitações, contratos e seus aditivos; e dados sobre funcionários municipais e do município.

A disseminação de informações governamentais é o processo de tornar possível o compartilhamento de dados sobre ações e decisões dos agentes públicos, gerados ou organizados por instituições governamentais. Compreende os resultados dos esforços e das iniciativas de divulgação à sociedade, das atividades próprias da administração pública, como as políticas públicas adotadas e o fornecimento de conteúdos que possam subsidiar os indivíduos no acompanhamento da atividade pública (LARA; CONTI, 2003).

Para atingir o usuário de maneira efetiva, inclusive no contexto governamental, Carvalho (2001) ressalta que as estratégias de disseminação precisam estar apoiadas tanto nos canais de comunicação quanto nas fontes de informação, destacando aspectos como a mediação exercida pelo profissional da informação, as fontes de informação, a comunicação informal e o uso da informação.

Davis Júnior, Souza e Borges (2005), ao tratarem sobre a disseminação de dados, ressaltam a importância da disponibilização de metadados junto aos recursos informacionais para facilitar a localização e a identificação das fontes de dados. Para estes autores, os metadados devem apresentar um bom nível de detalhamento, trazendo informações sobre a identificação dos dados, sua distribuição, organização e referências dos metadados.

O uso crescente de recursos tecnológicos para acesso a dados governamentais pode gerar demandas por mecanismos de serviços públicos de informação mais eficientes e transparentes. No Brasil, uma das primeiras iniciativas de se utilizar a internet, como meio para a disponibilização de dados públicos ocorreu em 1994, com o Portal da Transparência da ControladoriaGeral da União (PLATT NETO; CRUZ; VIEIRA, 2006). Com essa iniciativa, o país começou a incorporar os preceitos de Governo eletrônico, utilizando a internet para o compartilhamento de dados governamentais e a promoção do acompanhamento público das atividades realizadas no âmbito da administração pública. 
O Governo eletrônico envolve questões tecnológicas [como a utilização de recursos informáticos] e organizacionais [como a eficiência da administração pública]. Os objetivos almejados são: transparência, acessibilidade, prestação de contas, serviços públicos eficientes, políticas públicas e envolvimento dos usuários. Ao incorporar os preceitos do Governo eletrônico, as instituições governamentais podem buscar eficiência, eficácia e melhoria na qualidade da disponibilização das informações (ANDERSEN; HENRIKISEN, 2006).

Com a evolução do Governo eletrônico, no ano de 2011, o governo brasileiro firmou um compromisso internacional de Governo Aberto (Open Government Partnership), na qual o país é um dos estados fundadores. Para cumprimento dessa parceria, os sites oficiais do governo que tornam acessíveis seus conjuntos de dados devem atender aos oito princípios de dados abertos (THE ANNOTATED..., [2014]), utilizando tecnologias informacionais para ampliar a disponibilização, de modo que os cidadãos tenham condições para recuperar dados de interesse, atendendo suas necessidades informacionais (RODRIGUES; SANT’ANA, 2012).

Ao estudar o processo de compartilhamento de dados governamentais na internet, é possível observar que nem todos os princípios de dados abertos estão sendo atendidos, pois em muitos portais governamentais são publicados dados em formato fechado. Segundo Vaz, Ribeiro e Matheus (2010), são os órgãos governamentais que decidem o que e de que forma os conteúdos são vistos e devem, além de publicar os dados em formato aberto, proporcionar acesso às bases de dados de forma interativa, de modo que os usuários possam estruturar consultas e produzir cruzamentos específicos, propiciando aplicar filtros em buscas de informações detalhadas. Nessa perspectiva, as instituições devem ir além de oferecer serviços de visualização de dados, ofertando, também, serviços voltados às buscas avançadas, análise automatizada de conteúdo e cruzamento com outras fontes de dados simultaneamente (ROBINSON et al., 2009).

Além dos serviços de busca avançada, análise automatizada de conteúdo e recursos para visualização de dados, as instituições devem estimular a reutilização dos dados quando coletados. Rodrigues e Sant'Ana (2013) ressaltam que o fornecimento de dados reutilizáveis implica, necessariamente, 
na disponibilização de dados primários [mais granular e com maior nível de detalhamento], a fim de que sejam criadas oportunidades para a construção de novas percepções e visualizações.

No compartilhamento de dados governamentais na internet, um aspecto que também merece ser destacado é o problema da privacidade. Em algumas situações típicas, os usuários, para interagir com um serviço online, devem fornecer significativa quantidade de dados sensíveis, sendo que cada serviço tem sua própria política de privacidade envolvendo o uso, armazenamento e divulgação dos dados (MEDJAHED et al., 2003).

Muitos aspectos encontrados no processo de disponibilização e acesso a dados governamentais na internet envolvem fatores que podem ser mais bem compreendidos sob uma perspectiva interdisciplinar. Para tanto, é importante contextualizar a evolução do caráter interdisciplinar na Ciência da Informação, de modo a identificar quais são as áreas que apresentam relações de natureza interdisciplinar e evidenciar contribuições de disciplinas presentes nas estruturas curriculares dos cursos de graduação no Brasil com enfoque em Ciência da Informação para o estudo dos aspectos envolvidos nesse fluxo informacional.

\section{Interdisciplinaridade da Ciência da Informação}

A Ciência Clássica, segundo Morin e Le Moigne (2000), estabeleceu-se sob quatro pilares: a razão (como sistema de ideias coerentes ligadas por procedimentos lógicos de dedução ou indução que obedecem ao princípio da não contradição); a objetividade (operando a separação do sujeito/observador em relação ao objeto/observação); o empirismo (que induz a ideia de que as teorias, por serem validadas em observações e experimentações, refletem o real); e a lógica clássica (utilizada para verificar o sistema de ideias, levando a um nível de coerência para que se possa chegar à verdade).

Pinheiro (2006) explica que a divisão da Ciência em áreas específicas determina a especialização do conhecimento em domínios homogêneos de estudo, por meio de um conjunto sistemático e organizado, com características próprias no âmbito do ensino, da formação, dos métodos e das matérias. As 
áreas de conhecimento apresentam enfoques específicos, cujos objetos e fenômenos são reduzidos ao ângulo de visão particular de seus especialistas. A ampliação deste ângulo de visão no desenvolvimento da Ciência depende de interconexões entre distintas áreas.

Para ir ao encontro dessas interconexões é necessário desenvolver uma perspectiva sistêmica que, por sua vez, favorece o reconhecimento da complexidade de objetos e fenômenos estudados em qualquer área do conhecimento. A Teoria Geral dos Sistemas propõe o rompimento com o reducionismo, com o pensamento mecanicista e com o determinismo clássico, transformando os princípios organizadores do conhecimento (SANTOS; PELOSI; OLIVEIRA, 2012). A abordagem sistêmica aplicada à organização do conhecimento científico resulta na noção de interdisciplinaridade.

Para esta pesquisa, adota-se para definição de interdisciplinaridade o conceito de Pombo (2004) que aborda esta condição como sendo qualquer forma de combinação entre duas ou mais disciplinas, buscando a compreensão de um objeto a partir da confluência entre pontos de vistas distintos, resultando na elaboração de uma síntese comum do objeto.

A Ciência da Informação antes de ser considerada uma área interdisciplinar, pode ser compreendida como uma ciência consiliente [termo criado por Whewell, em 1840, e que significa um salto conjunto de conhecimento entre áreas, por meio da ligação de fatos e de teorias, buscando gerar novas bases explanatórias]. Por ter características de uma ciência consiliente, a Ciência da Informação é reconhecida como tal pelos próprios pesquisadores da área desde os primórdios (BRAGA, 1999 apud PINHEIRO, 2005).

Segundo Pinheiro (2005) a Ciência da Informação é interdisciplinar, pois inclui aspectos tanto das Ciências Naturais quanto das Humanidades e das Ciências Sociais. A mesma autora ressalta a importância de se ter em mente que o principal ponto é integrar o pensamento cientifico às perspectivas sociais e psicológicas, tanto no que tange a teoria quanto a prática. Saracevic (1995), ao apresentar três características da Ciência da Informação, destaca seu caráter 
interdisciplinar, assim como a sua relação com a tecnologia e a forte dimensão social e humana.

Muitas áreas tiveram papel fundamental na evolução da Ciência da Informação. Pinheiro (2006) definiu a constituição científica da Ciência da Informação analisando a construção do terreno epistemológico da área, e evidenciou 20 áreas do conhecimento que têm relação interdisciplinar com a Ciência da Informação: Administração, Economia, Ciência da Computação, Biblioteconomia, Linguística, Ciência Política, Direito, Arquivologia, Museologia, Psicologia, Filosofia, Epistemologia, Filosofia das Ciências, Matemática, Educação, Ética, Estatística, História da Ciência, Sociologia da Ciência e Comunicação.

Algumas das áreas indicadas por Pinheiro (2006), como interdisciplinares à Ciência da Informação, podem ser associadas ao estudo do fluxo informacional envolvendo o compartilhamento de dados governamentais na internet e, refletem suas contribuições por meio das disciplinas que compõem a estrutura curricular dos cursos de graduação com enfoque na área. Na Seção 4, apresentam-se a metodologia e os procedimentos metodológicos utilizados para o levantamento e a análise dos dados que embasaram o desenvolvimento dos resultados e discussões.

\section{Materiais e métodos}

A pesquisa é de natureza qualitativa, do tipo exploratória, cujo procedimento metodológico aplicado partiu de uma revisão bibliográfica em artigos de periódicos e livros para descrever o processo de compartilhamento de dados governamentais na internet, bem como discorrer sobre os fatores que implicam no caráter interdisciplinar da Ciência da Informação.

A literatura consultada forneceu subsídios para atender aos objetivos de identificar os campos de conhecimento que têm relação interdisciplinar com a Ciência da Informação e evidenciar quais deles podem contribuir para o estudo do compartilhamento de dados governamentais na internet. Especificamente, em 
obras como a de Pinheiro (2006) que identificou 20 áreas do conhecimento que têm relações interdisciplinares com a Ciência da Informação, e a de Moreira, Valentim e Sant'Ana (2016) que, a partir das 20 áreas citadas por Pinheiro (2006), indicaram oito delas como campos do conhecimento que podem contribuir com o estudo desse fluxo informacional.

Para atender ao objetivo de relacionar as disciplinas que compõem a estrutura curricular dos cursos de graduação em Ciência da Informação com os aspectos presentes no fluxo informacional em questão, foi aplicado o método de 'Análise de Conteúdo'. Ele consiste em técnicas para avaliar comunicações, visando obter, por meio de procedimentos sistemáticos e objetivos de descrição do conteúdo das mensagens, indicadores que propiciem a inferência de conhecimentos relativos às condições de produção/recepção (variáveis inferidas) dessas mensagens (BARDIN, 2009).

Para a aplicação do método optou-se pela técnica de 'Análise Categorial' que envolve a seleção de critérios de escolha e delimitação de categorias para associação do conteúdo presente nas mensagens analisadas, nesse caso, as mensagens de domínio textual. Para a definição das categorias que representam e agrupam os aspectos envolvidos no compartilhamento de dados governamentais na internet, foram utilizados os seguintes artigos presentes na revisão bibliográfica: Carvalho (2001); Lara e Conti (2003); Medjahed et al. (2003); Davis Jr., Souza e Borges (2005); Andersen e Henrikisen (2006); Robinson et al. (2009); Vaz, Ribeiro e Matheus (2010); Rodrigues e Sant'Ana (2012); e Rodrigues e Sant'Ana (2013).

Com as categorias definidas a priori, levantaram-se unidades de análise para realizar a inferência e a interpretação dos resultados, apresentando significados nas relações de conteúdo. As unidades de análise foram obtidas a partir de uma coleta de informações nos planos de ensino das disciplinas que compõem a estrutura curricular dos cursos de graduação em universidades públicas no Brasil, com enfoque em Ciência da Informação: o curso de bacharelado em "Biblioteconomia e Ciências da Informação e da Documentação" da Universidade de São Paulo (USP/Ribeirão Preto); o curso de 
bacharelado em "Biblioteconomia e Ciência da Informação", da Universidade Federal de São Carlos (UFSCar); e o curso de "Ciência da Informação", da Universidade Federal de Santa Catarina (UFSC).

A estrutura curricular das disciplinas e seus respectivos planos de ensino foram obtidos nos portais oficiais das instituições: USP (UNIVERSIDADE DE SÃO PAULO, [20--]), UFSCar (UNIVERSIDADE FEDERAL DE SÃO CARLOS, [20--]) e UFSC (UNIVERSIDADE FEDERAL DE SANTA CATARINA, 2017). Para o levantamento das unidades de análise, foram considerados trechos da ementa, do objetivo, da carga horária da disciplina e o professor responsável. Nos casos em que o nome do professor responsável pela disciplina não constava no plano de ensino disponibilizado, utilizou-se como documento para coleta de dados a relação de horários de aulas do semestre para obter esta informação, como no caso da UFSCar (UNIVERSIDADE FEDERAL DE SÃO CARLOS, [2017]). Destaca-se que os planos de ensino disponíveis no portal da USP/Ribeirão Preto não continham a ementa das disciplinas, portanto, este conteúdo para o levantamento das unidades de análise foi desconsiderado apenas neste caso. Além disso, foram desconsiderados os planos de ensino das disciplinas do quarto, quinto e sexto períodos do curso de Ciência da Informação (UFSC), uma vez que estavam disponíveis no portal oficial da instituição, até a data da coleta, somente os planos de ensino das disciplinas ofertadas em 2016 e no $1^{\circ}$ semestre de 2017.

O registro das unidades de análise estendeu-se para a Plataforma Lattes (BRASIL, [20--]), na qual foram obtidas informações referentes à formação graduação e pós-graduação - dos professores responsáveis pelas disciplinas que compunham as estruturas curriculares da área.

Para realizar as inferências e interpretações, as unidades de análise foram registradas em uma planilha eletrônica, a partir da qual foi elaborado um quadro contendo a associação destas com as categorias definidas a priori para representar os aspectos envolvidos no fluxo informacional estudado. A estrutura do Quadro 1 compreende os seguintes atributos: o título e a descrição das categorias definidas para representar os aspectos envolvido no 
compartilhamento de dados governamentais na internet; as áreas do conhecimento, interdisciplinares à Ciência da Informação que, segundo Moreira, Valentim e Sant'Ana (2016), podem contribuir com cada categoria definida; informações sobre as disciplinas evidenciadas como possíveis contributos para o estudo desse fluxo informacional, compostas pela instituição promotora, o nome da disciplina e carga horária total, os trechos da ementa e do objetivo que propiciaram sua associação com as categorias definidas; e o nome do(s) professor(es) responsável(eis), informações sobre sua formação, composta por graduação e pós-graduação (considerando o maior nível).

Para apresentar as análises realizadas a partir do Quadro 1, foram aplicados recursos de visualização de dados, como gráficos e um grafo. Por meio de uma planilha eletrônica, foram gerados dois gráficos no formato "radar", indicado para comparar várias séries de dados ao mesmo tempo. O primeiro foi gerado com o intuito de exibir a comparação dos três cursos analisados, considerando a somatória da carga horária das disciplinas evidenciadas como contributos para o estudo do compartilhamento de dados governamentais na internet. $\mathrm{O}$ segundo, por usa vez consolida o resultado dos três cursos, indicando quais categorias recebem maiores contribuições das disciplinas da Ciência da Informação, também, com base na quantificação da carga horária das disciplinas.

Para a elaboração do grafo, foi realizada a associação entre as categorias definidas com as áreas de formação (graduação e pós-graduação) dos professores responsáveis pelas disciplinas apontadas como contributos para o estudo do compartilhamento de dados governamentais na internet. A partir deste filtro, foi desenvolvida uma rede de relações entre as categorias e as áreas de formação dos professores responsáveis pelas disciplinas, utilizando o software UCINET (UCINET..., 2014) e seu recurso NETDRAW.

\section{Resultados e discussões}

A partir da identificação dos aspectos envolvidos no processo de compartilhamento de dados governamentais na internet, definiram-se sete 
categorias para representar este fluxo informacional: Comunicação pública; Estratégias de disseminação; Representação das bases e dos recursos informacionais; Iniciativas e políticas de publicação de dados; Infraestrutura e recursos de recuperação; Coleta e armazenamento dos dados; e Privacidade no acesso.

Moreira, Valentim e Sant'Ana (2016), embasados nas vinte áreas do conhecimento evidenciadas por Pinheiro (2006) como sendo interdisciplinares à Ciência da Informação, identificaram os principais temas de estudo tratados por cada uma e selecionaram oito delas como possível contributo para o estudo desse fluxo informacional: Comunicação, Ciência Política, Biblioteconomia, Arquivologia, Administração, Ciência da Computação, Direito e Estatística.

O Quadro 1 apresenta as categorias definidas a partir da literatura, juntamente com o trecho da descrição que propiciou sua definição (com base nos artigos descritos na Seção Materiais e Métodos), associando para cada uma, qual das oito áreas citadas por Moreira, Valentim e Sant'Ana (2016) podem contribuir com o estudo do respectivo aspecto. No Quadro 1 também se encontram as associações realizadas entre as categorias e as disciplinas da área consideradas como contributos teóricos e práticos para este contexto.

A categoria Comunicação pública foi definida com base nos aspectos descritos por Lara e Conti (2003) sobre o compartilhamento de dados governamentais como sendo um processo de divulgação do conhecimento gerado e/ou organizado por uma instituição pública à sociedade, e que está diretamente vinculado às práticas de gestão institucional. Para o estudo dos aspectos envolvidos por esta categoria, considera-se as contribuições das seguintes áreas destacadas por Moreira, Valentim e Sant'Ana (2016): a Comunicação que aborda a produção, veiculação e recepção de mensagens [divulgação] em meio a interação entre emissores [Governo] e receptores [sociedade]; e a Ciência Política que contribui com o estudo do comportamento dos atores políticos e do fortalecimento institucional feito mediante o processo comunicacional. Com base na formação dos professores responsáveis pelas disciplinas relacionadas com esta categoria, verificam-se contribuições da área 

contribuições no estudo do compartilhamento de dados governamentais na internet

Fábio Mosso Moreira, Marta Lígia Pomim Valentim e Ricardo César Gonçalves Sant'Ana

de Letras, Psicologia, Biblioteconomia e Documentação, Educação e a própria Ciência da Informação.

A categoria Estratégias de disseminação foi definida com base nos aspectos levantados por Carvalho (2001) que destaca a necessidade de articular uma estratégia de disseminação apoiada tanto nos canais de comunicação quanto nas fontes de informação, na mediação do profissional da informação, na comunicação informal e no uso da informação. Para o estudo dos aspectos envolvidos por essa categoria, consideram-se as contribuições das seguintes áreas destacadas por Moreira, Valentim e Sant'Ana (2016): a Biblioteconomia que fornece técnicas para viabilizar o uso por meio da identificação do conteúdo informacional e representação documental; a Arquivologia que trata da conservação e preservação dos documentos, podendo contribuir principalmente no âmbito da mediação da informação e no gerenciamento de fontes de informação; e a Comunicação que fornece elementos para elaboração de estratégias, considerando a participação social gerada pelo contato entre as pessoas, grupos e classes, entendidos neste contexto como as instituições governamentais e a sociedade. Com base na formação dos professores responsáveis pelas disciplinas relacionadas com esta categoria, verificam-se contribuições da área de Sociologia e Política, Engenharias, Comparative American Studies, Política Científica e Tecnológica, Biblioteconomia e Documentação, Calidad En La Educación Básica, e a própria Ciência da Informação. 
Quadro 1 - Associação das categorias com as áreas interdisciplinares à Ciência da Informação, as disciplinas que compõem a estrutura curricular da área e as áreas de formação dos professores responsáveis

\begin{tabular}{|c|c|c|c|c|c|c|c|c|c|}
\hline \multicolumn{2}{|c|}{$\begin{array}{l}\text { Aspectos do compartilhamento de } \\
\text { dados governamentais na Internet }\end{array}$} & \multirow{2}{*}{$\begin{array}{c}\text { Áreas do } \\
\text { conhecimento } \\
\text { que } \\
\text { contribuem } \\
\text { para o estudo } \\
\text { do } \\
\text { compartilhame } \\
\text { nto de dados } \\
\text { governamentai } \\
\text { s na Internet } \\
\text { (MOREIRA; } \\
\text { VALENTIM; } \\
\text { SANT'ANA, } \\
\text { 2016) }\end{array}$} & \multicolumn{5}{|c|}{ Disciplinas dos cursos de graduação em Ciência da Informação no Brasil } & \multicolumn{2}{|c|}{$\begin{array}{l}\text { Formação do(s) professor(es) } \\
\text { responsável(eis) }\end{array}$} \\
\hline Categoria & Descrição & & IES & $\begin{array}{l}\text { Disciplina } \\
\text { [Carga } \\
\text { Horária] }\end{array}$ & Trechos da Ementa & Trechos dos Objetivos & $\begin{array}{l}\text { Professor(es) } \\
\text { responsável(eis) }\end{array}$ & Graduação & $\begin{array}{c}\text { Pós- } \\
\text { Graduação }\end{array}$ \\
\hline \multirow{3}{*}{$\begin{array}{l}\text { Comunicação } \\
\text { pública }\end{array}$} & \multirow{3}{*}{$\begin{array}{c}\text { Divulgação à } \\
\text { sociedade das } \\
\text { atividades próprias } \\
\text { da administração } \\
\text { pública [...] varia } \\
\text { conforme sua } \\
\text { atividade básica, } \\
\text { seus objetivos e } \\
\text { percepção da } \\
\text { necessidade da } \\
\text { sociedade (LARA; } \\
\text { CONTI, 2003, p. } \\
\text { 26) }\end{array}$} & \multirow{3}{*}{$\begin{array}{l}\text { Comunicação / } \\
\text { Ciência Política }\end{array}$} & \multirow{2}{*}{ USP } & $\begin{array}{c}\text { Comunicação, } \\
\text { Linguagem e } \\
\text { Informação } \\
{[60 \mathrm{~h}]}\end{array}$ & N/D & $\begin{array}{l}\text { "Estudar a teoria } \\
\text { comunicacional }[\ldots . .] \\
\text { centrado nas noções de } \\
\text { mensagem, emissor, } \\
\text { receptor, código, canal e } \\
\text { referente." }\end{array}$ & $\begin{array}{l}\text { Lucília Maria } \\
\text { Abrahão e Sousa }\end{array}$ & Letras & Psicologia \\
\hline & & & & $\begin{array}{l}\text { Cultura, } \\
\text { Sociedade e } \\
\text { Informação } \\
{[90 \mathrm{~h}]}\end{array}$ & N/D & $\begin{array}{l}\text { "Processos de construção } \\
\text { social de conhecimentos e } \\
\text { significações [...] } \\
\text { consideradas as condições } \\
\text { de produção, distribuição e } \\
\text { recepção de informações." }\end{array}$ & $\begin{array}{l}\text { Solange Puntel } \\
\text { Mostafa }\end{array}$ & $\begin{array}{l}\text { Biblioteconomia e } \\
\text { Documentação }\end{array}$ & Educação \\
\hline & & & UFSCar & $\begin{array}{c}\text { Estudos da } \\
\text { linguagem em } \\
\text { Ciência da } \\
\text { Informação } \\
\text { [60h] }\end{array}$ & $\begin{array}{c}\text { "Linguística; } \\
\text { sociolingüística, filosofia } \\
\text { da linguagem, teoria da } \\
\text { comunicação, linguagem } \\
\text { natural, linguagem } \\
\text { artificial; signo, }\end{array}$ & $\begin{array}{l}\text { "Conhecer teorias, } \\
\text { metodologias e conceitos } \\
\text { relacionados aos estudos da } \\
\text { lingüística e da filosofia da } \\
\text { linguagem [...]" }\end{array}$ & $\begin{array}{l}\text { Luciana de Souza } \\
\text { Gracioso }\end{array}$ & $\begin{array}{l}\text { Biblioteconomia e } \\
\text { Documentação }\end{array}$ & $\begin{array}{l}\text { Ciência da } \\
\text { Informação }\end{array}$ \\
\hline
\end{tabular}




\begin{tabular}{|c|c|c|c|c|c|c|c|c|c|}
\hline & & & & & $\begin{array}{l}\text { significante, significado, } \\
\text { contexto, referência }[\ldots] \text { ". }\end{array}$ & & & & \\
\hline \multirow{5}{*}{$\begin{array}{l}\text { Estratégias de } \\
\text { disseminação }\end{array}$} & \multirow{5}{*}{$\begin{array}{c}\text { Estratégias de } \\
\text { disseminação [...] } \\
\text { apoiadas tanto nos } \\
\text { canais de } \\
\text { comunicação quanto } \\
\text { nas fontes. [...] } \\
\text { merecem ser } \\
\text { destacados alguns } \\
\text { aspectos } \\
\text { importantes, tais } \\
\text { como a mediação } \\
\text { exercida pelo } \\
\text { profissional da } \\
\text { informação, as } \\
\text { fontes de } \\
\text { informação, a } \\
\text { comunicação } \\
\text { informal e o uso da } \\
\text { informação } \\
\text { (CARVALHO, } \\
\text { 2001, p.5-6) }\end{array}$} & \multirow{5}{*}{$\begin{array}{c}\text { Comunicação / } \\
\text { Arquivologia / } \\
\text { Biblioteconomia }\end{array}$} & \multirow{2}{*}{ USP } & $\begin{array}{c}\text { Mediação e } \\
\text { Recepção de } \\
\text { Informação } \\
\text { [60h] }\end{array}$ & $\mathrm{N} / \mathrm{D}$ & $\begin{array}{l}\text { "Estudo dos processos de } \\
\text { mediação e recepção de } \\
\text { informação, tendo em vista } \\
\text { o mapeamento das práticas } \\
\text { e usos sociais da cultura." }\end{array}$ & $\begin{array}{l}\text { Silvia Maria do } \\
\text { Espirito Santo }\end{array}$ & $\begin{array}{l}\text { Sociologia e } \\
\text { politica }\end{array}$ & $\begin{array}{l}\text { Ciência da } \\
\text { Informação }\end{array}$ \\
\hline & & & & $\begin{array}{c}\text { Planejamento } \\
\text { e Informação } \\
{[90 \mathrm{~h}]}\end{array}$ & N/D & $\begin{array}{l}\text { Apresentar [...] conceitos e } \\
\text { as técnicas fundamentais } \\
\text { do processo de } \\
\text { planejamento estratégico de } \\
\text { Unidades de Informação } \\
\text { (UIs). }\end{array}$ & $\begin{array}{c}\text { Leonardo } \\
\text { Guimarães Garcia }\end{array}$ & $\begin{array}{l}\text { Engenharia de } \\
\text { Materiais }\end{array}$ & $\begin{array}{c}\text { Ciência e } \\
\text { Engenharia } \\
\text { dos } \\
\text { Materiais }\end{array}$ \\
\hline & & & \multirow[t]{3}{*}{ UFSCar } & $\begin{array}{c}\text { Usos e } \\
\text { usuários da } \\
\text { informação } \\
\text { [60h] }\end{array}$ & $\begin{array}{c}\text { “[...] estudos de usuário e } \\
\text { comunidade usuária, } \\
\text { físicos e virtuais; } \\
\text { necessidades e demandas } \\
\text { de informação; } \\
\text { comportamento e atitudes } \\
\text { de busca e uso de } \\
\text { informação, competência } \\
\text { informacional, educação } \\
\text { de usuário." }\end{array}$ & $\begin{array}{l}\text { "[...] estudar e desenvolver } \\
\text { metodologias para } \\
\text { diagnóstico e avaliação das } \\
\text { necessidades de } \\
\text { informação; reconhecer } \\
\text { atitudes e comportamentos } \\
\text { de busca e uso da } \\
\text { informação." }\end{array}$ & $\begin{array}{l}\text { Ariadne Chloë } \\
\text { Mary Furnival }\end{array}$ & $\begin{array}{c}\text { Comparative } \\
\text { American Studies. }\end{array}$ & $\begin{array}{c}\text { Política } \\
\text { Científica e } \\
\text { Tecnológica }\end{array}$ \\
\hline & & & & \multirow{2}{*}{$\begin{array}{c}\text { Gestão de } \\
\text { unidades de } \\
\text { informação e } \\
\text { do } \\
\text { conhecimento } \\
\text { [60h] }\end{array}$} & \multirow{2}{*}{$\begin{array}{c}\text { "Gestão e avaliação de } \\
\text { processos e recursos para } \\
\text { a geração de produtos e } \\
\text { serviços [...] planejamento } \\
\text { em unidades de } \\
\text { informação. Estratégias de } \\
\text { tomada de decisão." }\end{array}$} & \multirow{2}{*}{$\begin{array}{l}\text { "Diagnóstico, } \\
\text { planejamento, avaliação de } \\
\text { recursos, processos de } \\
\text { aprendizagem e inovação e } \\
\text { as estratégias de tomada de } \\
\text { decisão." }\end{array}$} & $\begin{array}{c}\text { Wanda Aparecida } \\
\text { Machado } \\
\text { Hoffmann }\end{array}$ & $\begin{array}{l}\text { Engenharia } \\
\text { Metalúrgica }\end{array}$ & $\begin{array}{c}\text { Ciências e } \\
\text { Engenharia } \\
\text { dos } \\
\text { Materiais }\end{array}$ \\
\hline & & & & & & & $\begin{array}{c}\text { Gilberto } \\
\text { Domingues Junior }\end{array}$ & $\begin{array}{l}\text { Engenharia de } \\
\text { Produção } \\
\text { Agroindustrial }\end{array}$ & $\begin{array}{l}\text { Engenharia } \\
\text { Mecânica }\end{array}$ \\
\hline
\end{tabular}




\begin{tabular}{|c|c|c|c|c|c|c|c|c|c|}
\hline & & & & \multirow{2}{*}{$\begin{array}{l}\text { Serviço de } \\
\text { referência e } \\
\text { fontes de } \\
\text { informação } \\
\quad[60 \mathrm{~h}]\end{array}$} & \multirow{2}{*}{$\begin{array}{c}\text { "Diagnóstico, } \\
\text { caracterização e } \\
\text { conhecimento dos } \\
\text { Serviços de Referência e } \\
\text { as Fontes de informação } \\
\text { [...] Estratégias de } \\
\text { disseminação seletiva da } \\
\text { informação." }\end{array}$} & \multirow{2}{*}{$\begin{array}{l}\text { “Otimizar os produtos e } \\
\text { serviços de informação a } \\
\text { partir de estratégias de } \\
\text { marketing, publicidade e } \\
\text { comunicação e ainda para } \\
\text { otimizar ações de } \\
\text { promoção de uso de } \\
\text { informação na sociedade } \\
\text { em geral." }\end{array}$} & $\begin{array}{l}\text { Ariadne Chloë } \\
\text { Mary Furnival }\end{array}$ & $\begin{array}{c}\text { Comparative } \\
\text { American Studies. }\end{array}$ & $\begin{array}{c}\text { Política } \\
\text { Científica e } \\
\text { Tecnológica }\end{array}$ \\
\hline & & & & & & & $\begin{array}{l}\text { Luciana de Souza } \\
\text { Gracioso }\end{array}$ & $\begin{array}{l}\text { Biblioteconomia e } \\
\text { Documentação }\end{array}$ & $\begin{array}{c}\text { Ciência da } \\
\text { Informação }\end{array}$ \\
\hline & & & \multirow{3}{*}{ UFSC } & $\begin{array}{l}\text { Fontes de } \\
\text { Informação I } \\
\text { [72h] }\end{array}$ & $\begin{array}{l}\text { “[...] Apresenta a tipologia } \\
\text { e finalidade das fontes de } \\
\text { informação. Analisa e } \\
\text { avalia as fontes de } \\
\text { informação gerais." }\end{array}$ & $\begin{array}{c}\text { "Avaliação e ao uso das } \\
\text { fontes de informação gerais } \\
\text { de referência." }\end{array}$ & Juliana Fachin & Biblioteconomia & $\begin{array}{l}\text { Ciência da } \\
\text { Informação }\end{array}$ \\
\hline & & & & \multirow{2}{*}{$\begin{array}{c}\text { Recuperação } \\
\text { da Informação } \\
\text { [72h] }\end{array}$} & \multirow{2}{*}{$\begin{array}{c}\text { "Estratégias [...] em bases } \\
\text { de dados. Recuperação da } \\
\text { informação na Web, dos } \\
\text { motores de busca, dos } \\
\text { diretórios e dos } \\
\text { metabuscadores." }\end{array}$} & \multirow{2}{*}{$\begin{array}{l}\text { "Desenvolver } \\
\text { competências } \\
\text { informacionais na } \\
\text { recuperação da } \\
\text { informação." }\end{array}$} & $\begin{array}{c}\text { Luciane Paula } \\
\text { Vital }\end{array}$ & Biblioteconomia & $\begin{array}{l}\text { Ciência da } \\
\text { Informaçãoo }\end{array}$ \\
\hline & & & & & & & $\begin{array}{l}\text { Angel Freddy } \\
\text { Godoy Viera }\end{array}$ & $\begin{array}{l}\text { Calidad En La } \\
\text { Educación Básica }\end{array}$ & $\begin{array}{l}\text { Engenharia } \\
\text { de Produção }\end{array}$ \\
\hline \multirow[b]{2}{*}{$\begin{array}{l}\text { Representação } \\
\text { dos recursos } \\
\text { informacionais }\end{array}$} & \multirow{2}{*}{$\begin{array}{c}\text { Os metadados } \\
\text { apresentam bom } \\
\text { nível de } \\
\text { detalhamento, e } \\
\text { trazem informações } \\
\text { sobre a identificação } \\
\text { dos dados, sua } \\
\text { distribuição e as } \\
\text { referências dos } \\
\text { metadados (DAVIS } \\
\text { JR; SOUZA; } \\
\text { BORGES, 2005, } \\
\text { p.358). }\end{array}$} & \multirow[b]{2}{*}{ Biblioteconomia } & USP & $\begin{array}{c}\text { Representação } \\
\text { Descritiva II } \\
{[90 \mathrm{~h}]}\end{array}$ & $\mathrm{N} / \mathrm{D}$ & $\begin{array}{l}\text { "Processos e instrumentos } \\
\text { adotados na estruturação do } \\
\text { registro de informação e na } \\
\text { representação descritiva no } \\
\text { meio eletrônico [...]" }\end{array}$ & $\begin{array}{l}\text { Marcia Regina da } \\
\text { Silva }\end{array}$ & $\begin{array}{l}\text { Biblioteconomia e } \\
\text { Ciência da } \\
\text { Informação }\end{array}$ & Educação \\
\hline & & & UFSCar & $\begin{array}{c}\text { Linguagens } \\
\text { documentárias } \\
\text { III [60h] }\end{array}$ & $\begin{array}{l}\text { "Web semântica e os } \\
\text { aspectos interdisciplinares } \\
\text { na representação de } \\
\text { recursos informacionais. } \\
\text { Apresentação e } \\
\text { caracterização das } \\
\text { linguagens de } \\
\text { representação na web." }\end{array}$ & $\begin{array}{c}\text { "Linguagens para } \\
\text { representação temática de } \\
\text { recursos informacionais na } \\
\text { web; [...] procedimentos, as } \\
\text { metodologias e os } \\
\text { softwares de construção de } \\
\text { linguagens de } \\
\text { representação temática na }\end{array}$ & $\begin{array}{c}\text { Rogério } \\
\text { Aparecido Sá } \\
\text { Ramalho }\end{array}$ & $\begin{array}{l}\text { Ciência da } \\
\text { Computação }\end{array}$ & $\begin{array}{l}\text { Ciência da } \\
\text { Informação }\end{array}$ \\
\hline
\end{tabular}




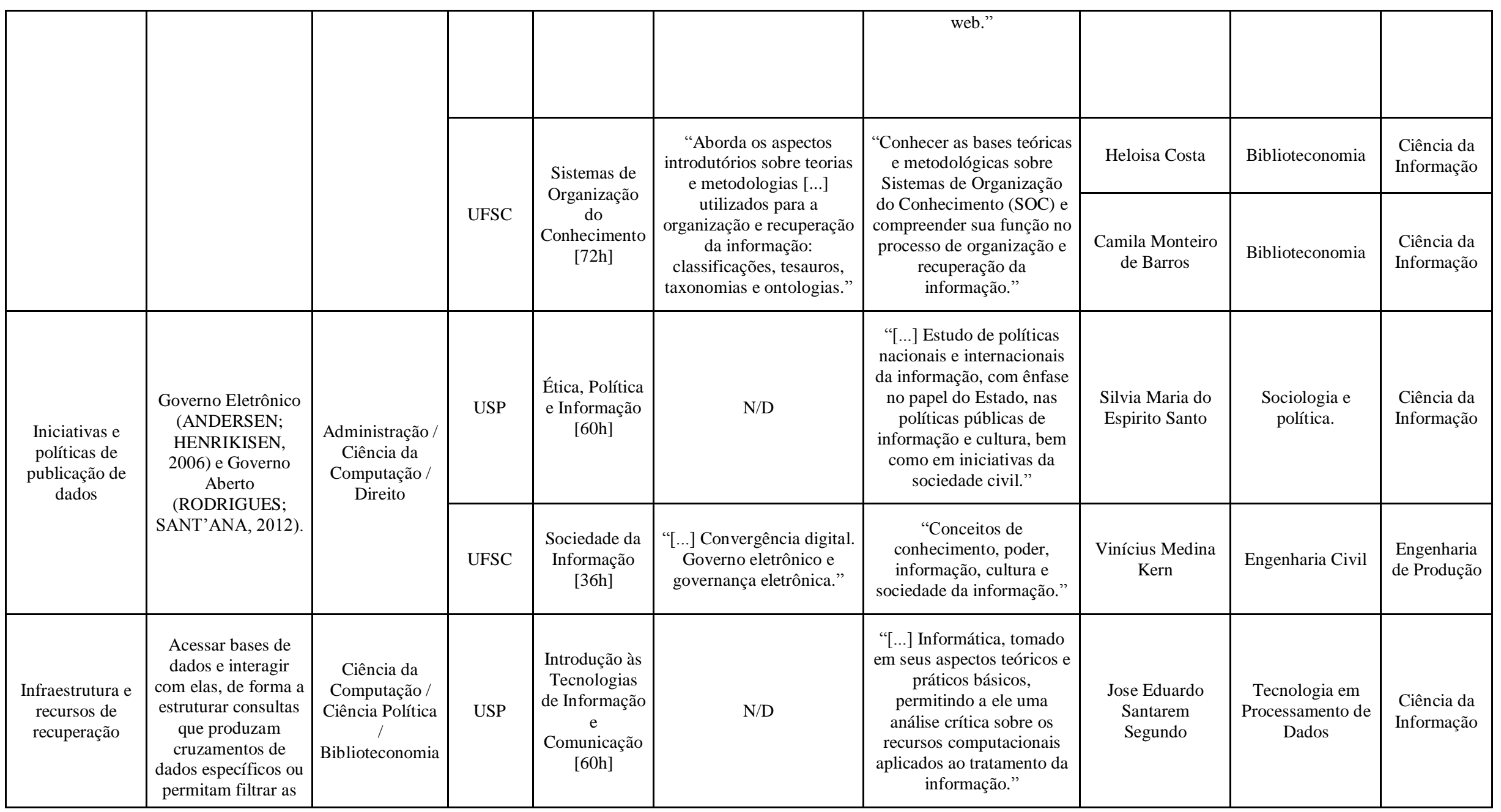




\begin{tabular}{|c|c|c|c|c|c|c|c|c|c|}
\hline & $\begin{array}{c}\text { bases de dados em } \\
\text { busca de } \\
\text { informações } \\
\text { detalhadas (VAZ; } \\
\text { RIBEIRO; } \\
\text { MATHEUS, 2010, } \\
\text { p.45-46). Buscas } \\
\text { avançadas, análise } \\
\text { automatizada de }\end{array}$ & & UFSCar & $\begin{array}{c}\text { Tecnologia da } \\
\text { Informação e } \\
\text { Comunicação } \\
\text { I [60h] }\end{array}$ & $\begin{array}{l}\text { "[...] sistemas para } \\
\text { disseminação da } \\
\text { informação." }\end{array}$ & $\begin{array}{l}\text { "Quadro conceitual sobre } \\
\text { Tecnologias de Informação } \\
\text { e Comunicação [...]" }\end{array}$ & $\begin{array}{c}\text { Leandro } \\
\text { Innocentini Lopes } \\
\text { de Faria }\end{array}$ & $\begin{array}{l}\text { Engenharia de } \\
\text { Materiais }\end{array}$ & $\begin{array}{c}\text { Ciência e } \\
\text { Engenharia } \\
\text { dos } \\
\text { Materiais }\end{array}$ \\
\hline & $\begin{array}{l}\text { conteúdo, e } \\
\text { cruzamento com } \\
\text { outras fontes de } \\
\text { dados de forma } \\
\text { simultânea } \\
\text { (ROBINSON et al., } \\
\text { 2009, p.161). }\end{array}$ & & UFSC & $\begin{array}{c}\text { Introdução às } \\
\text { Tecnologias } \\
\text { de Informação } \\
\text { e } \\
\text { Comunicação } \\
\text { [36h] }\end{array}$ & $\begin{array}{l}\text { "Introdução aos sistemas } \\
\text { de informação. } \\
\text { Fundamentos das } \\
\text { tecnologias da informação } \\
\text { e comunicação." }\end{array}$ & $\begin{array}{l}\text { "Compreender os } \\
\text { fundamentos dos sistemas } \\
\text { de informação e das } \\
\text { tecnologias da informação } \\
\text { e comunicação." }\end{array}$ & $\begin{array}{l}\text { Douglas Dyllon } \\
\text { Jeronimo de } \\
\text { Macedo }\end{array}$ & $\begin{array}{c}\text { Tecnologia em } \\
\text { Processamento de } \\
\text { Dados }\end{array}$ & $\begin{array}{l}\text { Engenharia e } \\
\text { Gestão do } \\
\text { Conhecimen } \\
\text { to }\end{array}$ \\
\hline \multirow{4}{*}{$\begin{array}{l}\text { Coleta e } \\
\text { armazenamento } \\
\text { dos dados }\end{array}$} & \multirow{4}{*}{$\begin{array}{l}\text { Devem contemplar a } \\
\text { possibilidade de } \\
\text { coleta de dados } \\
\text { primários (mais } \\
\text { granular), com o } \\
\text { maior nível de } \\
\text { detalhamento - para } \\
\text { criar oportunidades } \\
\text { de construções de } \\
\text { novas percepções e } \\
\text { visualizaçôes } \\
\text { (RODRIGUES; } \\
\text { SANT'ANA, 2013, } \\
\text { p.473). }\end{array}$} & \multirow{4}{*}{ Estatística } & \multirow{2}{*}{ USP } & \multirow{2}{*}{$\begin{array}{l}\text { Introdução à } \\
\text { Estatística } \\
{[30 \mathrm{~h}]}\end{array}$} & \multirow{2}{*}{ N/D } & \multirow{2}{*}{$\begin{array}{c}\text { “[...] noções de estatística } \\
\text { descritiva: tipos de dados e } \\
\text { suas representações } \\
\text { tabulares, gráficas e } \\
\text { numéricas; noções de } \\
\text { amostragem; significado } \\
\text { das curvas de distribuição } \\
\text { de probabilidade; noções } \\
\text { de correlação e análise de } \\
\text { regressão." }\end{array}$} & $\begin{array}{l}\text { Antônio Carlos } \\
\text { Roque da Silva } \\
\text { Filho }\end{array}$ & Física & $\begin{array}{l}\text { Cognitive } \\
\text { Science And } \\
\text { Artificial } \\
\text { Intelligence }\end{array}$ \\
\hline & & & & & & & $\begin{array}{l}\text { Nelson Augusto } \\
\text { Alves }\end{array}$ & Física & Física \\
\hline & & & UFSCar & $\begin{array}{l}\text { Lógica e base } \\
\text { de dados } \\
\text { aplicados à } \\
\text { Ciência da } \\
\text { Informação } \\
\text { [60h] }\end{array}$ & $\begin{array}{c}\text { “[...] conceitos básicos } \\
\text { sobre bases de dados, } \\
\text { organização de arquivos, } \\
\text { modelos de dados, } \\
\text { modelagem de dados, } \\
\text { projeto e implementação } \\
\text { de base de dados [...]" }\end{array}$ & $\begin{array}{c}\text { "Explicar os conceitos } \\
\text { teórico-metodológicos que } \\
\text { fundamentam o } \\
\text { desenvolvimento e } \\
\text { utilização de sistemas } \\
\text { banco de dados." }\end{array}$ & $\begin{array}{l}\text { Rogério } \\
\text { Aparecido Sá } \\
\text { Ramalho }\end{array}$ & $\begin{array}{l}\text { Ciência da } \\
\text { Computação }\end{array}$ & $\begin{array}{l}\text { Ciência da } \\
\text { Informação }\end{array}$ \\
\hline & & & UFSC & $\begin{array}{c}\text { Lógica } \\
\text { Instrumental I }\end{array}$ & $\begin{array}{l}\text { "Introdução ao Raciocínio } \\
\text { Lógico-Matemático. }\end{array}$ & $\begin{array}{l}\text { "Desenvolver o raciocínio } \\
\text { lógico-matemático e }\end{array}$ & $\begin{array}{c}\text { William Barbosa } \\
\text { Vianna }\end{array}$ & Filosofia & $\begin{array}{l}\text { Engenharia } \\
\text { de Produção }\end{array}$ \\
\hline
\end{tabular}




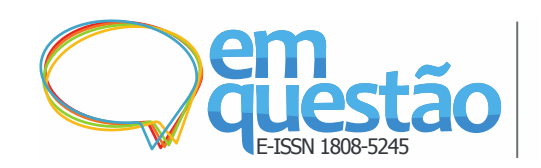

A interdisciplinaridade da Ciência da Informação e suas contribuições no estudo do compartilhamento de dados

\section{governamentais na internet}

Fábio Mosso Moreira, Marta Lígia Pomim Valentim e Ricardo César Gonçalves Sant'Ana

\begin{tabular}{|c|c|c|c|c|c|c|c|c|c|}
\hline & & & & {$[36 \mathrm{~h}]$} & $\begin{array}{c}\text { Teoria de Conjuntos. } \\
\text { Lógica Proposicional. } \\
\text { Cálculo de Predicados. } \\
\text { Análise e Validação de } \\
\text { Argumentos. Introdução } \\
\text { ao Pensamento Dedutivo." }\end{array}$ & $\begin{array}{l}\text { capacidade de reconhecer e } \\
\text { analisar sentenças } \\
\text { dedutivas com rigor, } \\
\text { clareza e precisão [...] } \\
\text { questões relacionadas ao } \\
\text { raciocínio lógico- } \\
\text { matemático e a análise e } \\
\text { resolução de argumentos } \\
\text { lógicos." }\end{array}$ & $\begin{array}{l}\text { Moisés Lima } \\
\text { Dutra }\end{array}$ & $\begin{array}{l}\text { Ciência da } \\
\text { Computação }\end{array}$ & $\begin{array}{l}\text { Ciência da } \\
\text { Computação }\end{array}$ \\
\hline & & & & $\begin{array}{c}\text { Introdução a } \\
\text { Bancos de } \\
\text { Dados [36h] }\end{array}$ & $\begin{array}{c}\text { "Bancos de Dados e Bases } \\
\text { de Dados" }\end{array}$ & $\begin{array}{l}\text { "Conhecer as bases teóricas } \\
\text { e as práticas de projeto de } \\
\text { utilização de bancos de } \\
\text { dados." }\end{array}$ & $\begin{array}{l}\text { Vinícius Medina } \\
\text { Kern }\end{array}$ & Engenharia Civil & $\begin{array}{l}\text { Engenharia } \\
\text { de Produção }\end{array}$ \\
\hline $\begin{array}{l}\text { Privacidade no } \\
\text { acesso }\end{array}$ & $\begin{array}{l}\text { Dados sensíveis } \\
\text { para interagir com } \\
\text { serviços online; } \\
\text { política de } \\
\text { privacidade } \\
\text { envolvendo o uso, } \\
\text { armazenamento e } \\
\text { divulgação dos } \\
\text { dados (MEDJAHED } \\
\text { et al., 2003). }\end{array}$ & $\begin{array}{c}\text { Direito / } \\
\text { Comunicação }\end{array}$ & UFSCar & $\begin{array}{c}\text { Gestão da } \\
\text { informação e } \\
\text { gestão de } \\
\text { redes de } \\
\text { pessoas e } \\
\text { organizações } \\
\text { [60h] }\end{array}$ & $\begin{array}{c}\text { "Recursos interativos e } \\
\text { colaborativos da web. } \\
\text { Cooperação e intercâmbio } \\
\text { entre unidades de } \\
\text { informação [...] } \\
\text { Mapeamento de redes para } \\
\text { o compartilhamento de } \\
\text { informações e } \\
\text { conhecimento." }\end{array}$ & $\begin{array}{l}\text { "Identificar as dinâmicas e } \\
\text { estratégias que facilitam a } \\
\text { integração, em rede, as } \\
\text { unidades e serviços de } \\
\text { informação existente em } \\
\text { um determinado contexto." }\end{array}$ & $\begin{array}{l}\text { Roniberto Morato } \\
\text { do Amaral }\end{array}$ & $\begin{array}{l}\text { Biblioteconomia e } \\
\text { Ciência da } \\
\text { Informação }\end{array}$ & $\begin{array}{l}\text { Engenharia } \\
\text { de Produção }\end{array}$ \\
\hline
\end{tabular}

Fonte: Dados da pesquisa

Legenda: Não disponibilizado (N/D). 
A categoria Representação dos recursos informacionais foi definida com base nos aspectos relacionados à descrição do conteúdo disseminado pelas organizações públicas, destacados por Davis Júnior, Souza e Borges (2005) que ressaltam o papel dos metadados para representação das fontes e dos recursos, a fim de facilitar sua localização e identificação. Para o estudo dos aspectos envolvidos por esta categoria, consideram-se contribuições da seguinte área destacada por Moreira, Valentim e Sant'Ana (2016): a Biblioteconomia, área que aborda a linguagem documental e a relação semântica entre os recursos para viabilizar a identificação da informação. Com base na formação dos professores responsáveis pelas disciplinas relacionadas com esta categoria, verificam-se contribuições da área de Biblioteconomia, Educação, Ciência da Computação e a própria Ciência da Informação.

A categoria Iniciativas e políticas de publicação de dados foi definida com base nos aspectos relacionados às ações formais de promoção da transparência pública, por meio do uso de tecnologias para disponibilização de dados, a exemplo do Governo Eletrônico (ANDERSEN; HENRIKSEN, 2006) e do movimento Governo Aberto (RODRIGUES; SANT'ANA, 2012). Para o estudo dos aspectos envolvidos por esta categoria, consideram-se contribuições das seguintes áreas destacadas por Moreira, Valentim e Sant'Ana (2016): a Ciência da Computação que aborda o desenvolvimento de artefatos computacionais e as estruturas de informações; a Administração que abrange os processos de gestão e organização produtiva; e o Direito que pode fornecer perspectivas para definição e avaliação de leis e políticas, buscando garantir o atendimento destes princípios uma vez que a área trata de sistemas e normas jurídicas, podendo ser legítimas ou não em sua formação. Com base na formação dos professores responsáveis pelas disciplinas relacionadas com esta categoria, verificam-se contribuições da área de Sociologia e política, Engenharias e a própria Ciência da Informação.

A categoria Infraestrutura e recursos de recuperação foi definida com base nos aspectos apontados por Vaz, Ribeiro e Matheus (2010) e Robinson et al. (2009), que destacam a necessidade de uma infraestrutura técnica adequada para publicação de dados governamentais na internet, por meio do fornecimento 
de serviços de informação. Para o estudo dos aspectos envolvidos por esta categoria, consideram-se contribuições das seguintes áreas destacadas por Moreira, Valentim e Sant'Ana (2016): a Ciência da Computação, no que se refere à observação dos artefatos computacionais para apoiar a infraestrutura técnica de compartilhamento de dados, a Ciência Política que pode contribuir para a identificação dos critérios envolvidos para seleção do conteúdo compartilhado, pois aborda o comportamento dos atores políticos e as formas de democratização da política, e a Biblioteconomia que pode fornecer métodos e técnicas para representar os recursos informacionais, proporcionando relações semânticas e associações entre datasets de fontes internas ou externas. Com base na formação dos professores responsáveis pelas disciplinas relacionadas a esta categoria, verificam-se contribuições da área de Tecnologia em Processamento de Dados, Engenharias, e a própria Ciência da Informação.

A categoria Coleta e armazenamento dos dados foi definida com base nos estudos de Rodrigues e Sant'Ana (2013) que destacam a importância da disponibilização de conjuntos de dados primários, que são dados com granularidade fina, para proporcionar processamentos e combinações variadas durante a recuperação. Para o estudo dos aspectos envolvidos por esta categoria, consideram-se contribuições da seguinte área destacada por Moreira, Valentim e Sant'Ana (2016): a Estatística por ser uma área que aborda técnicas para obtenção, organização, análise e apresentação de dados, podendo contribuir com a definição das possíveis análises que um conjunto de dados primários deverá proporcionar. Com base na formação dos professores responsáveis pelas disciplinas relacionadas a esta categoria, verificam-se contribuições da área de Física, Cognitive Science and Artificial Intelligence (CSAI), Ciência da Computação, Filosofia, Engenharias, e a própria Ciência da Informação.

A categoria Privacidade no acesso foi definida com base em Medjahed et al. (2003) que alertam para o fornecimento de informações pessoais durante a utilização dos serviços de disponibilização online, sendo considerado um aspecto importante que deve ser observado pelas instituições públicas durante a definição das políticas de acesso. Para o estudo dos aspectos envolvidos por esta categoria, consideram-se contribuições das seguintes áreas destacadas por 

contribuições no estudo do compartilhamento de dados governamentais na internet

Fábio Mosso Moreira, Marta Lígia Pomim Valentim e Ricardo César Gonçalves Sant'Ana

Moreira, Valentim e Sant'Ana (2016): o Direito que trabalha com normas e sistemas jurídicos, na busca pela segurança e proteção de direitos; e a Comunicação que trata da produção e veiculação de mensagens entre emissores e receptores, podendo contribuir com o estudo das Políticas de Privacidade e Termos de Uso em que cada instituição utiliza em seu portal oficial. Com base na formação dos professores responsáveis pelas disciplinas relacionadas a esta categoria, verificam-se contribuições da área de Biblioteconomia, Engenharias e a própria Ciência da Informação.

Para demonstrar as contribuições das disciplinas que compõem a estrutura curricular dos três cursos de graduação analisados nesta pesquisa, elaborou-se um gráfico (Figura 1) no formato radar, indicando para cada categoria qual instituição mais se destaca em sua estrutura curricular, tendo como base a somatória das cargas horárias das disciplinas elencadas. Observa-se que as três instituições apresentam representatividade similar para o estudo dos aspectos relacionados com a categoria Infraestrutura e recursos de recuperação.

Figura 1 - Contribuições (em carga horária) das disciplinas que compõem a estrutura curricular de cada um dos três cursos de graduação com ênfase em Ciência da Informação analisados

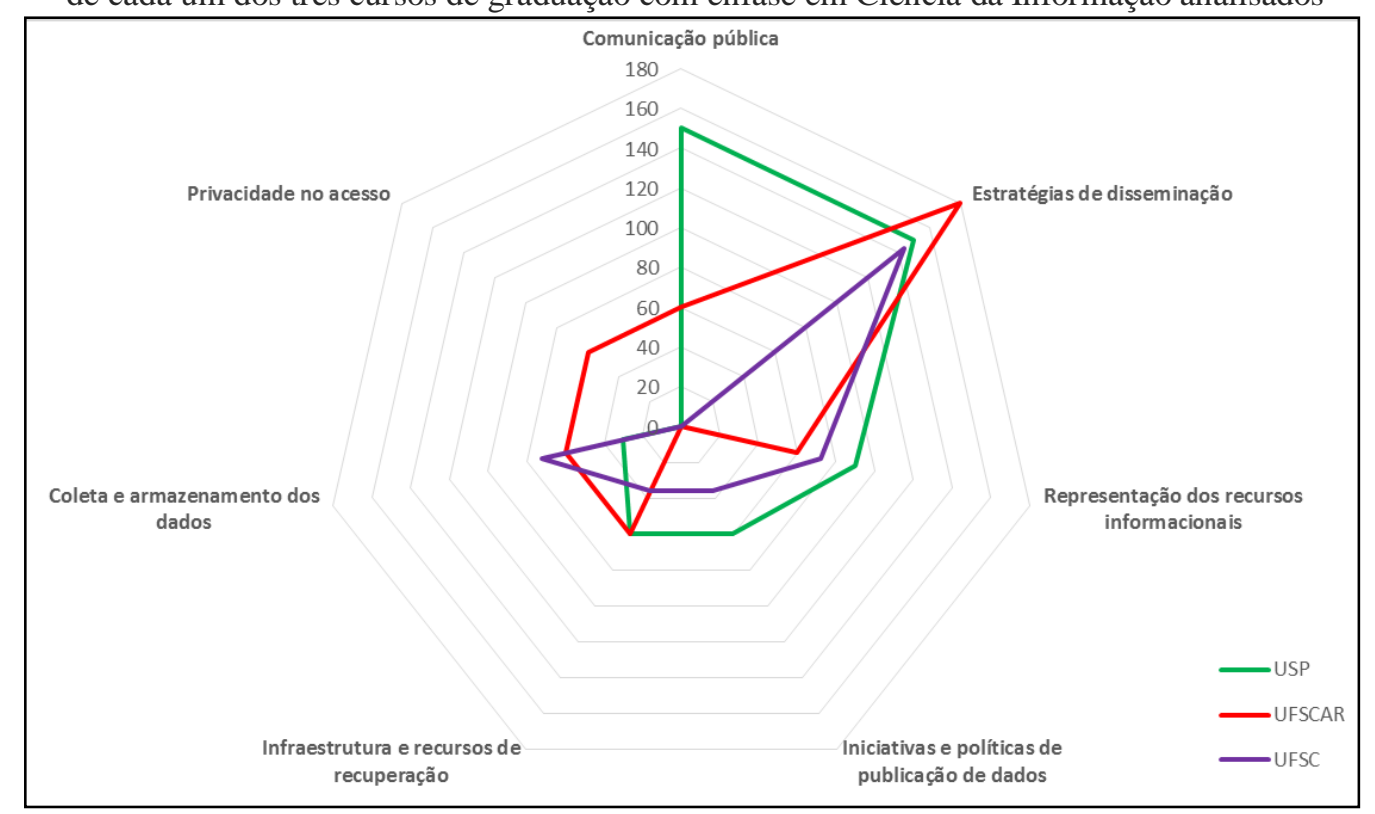

Fonte: Dados da pesquisa 

contribuições no estudo do compartilhamento de dados governamentais na internet

Fábio Mosso Moreira, Marta Lígia Pomim Valentim e Ricardo César Gonçalves Sant'Ana

Observa-se, a partir da Figura 1, que a estrutura curricular do curso de Biblioteconomia e Ciência da Informação e da Documentação (USP/Ribeirão Preto) destaca-se no estudo dos aspectos relacionados às categorias Representação dos recursos informacionais, Iniciativas e políticas de publicação de dados e Comunicação pública (com destaque); enquanto o curso de Biblioteconomia e Ciência da Informação (UFSCar) destaca-se no estudo dos aspectos envolvidos nas categorias Estratégias de disseminação e Privacidade no acesso (com destaque); e o curso de Ciência da Informação (UFSC) se destaca no estudo dos aspectos envolvidos na categoria Coleta e armazenamento dos dados.

Para demonstrar quais categorias recebem maiores contribuições das disciplinas da área da Ciência da Informação, também com base na quantificação da carga horária das disciplinas que compõem a estrutura curricular dos cursos analisados, elaborou-se um segundo gráfico para consolidar os três cursos analisados (Figura 2). Observa-se que a categoria que mais recebe contribuições das disciplinas que compõem a Ciência da Informação é Estratégias de disseminação, seguida pelas categorias Representação dos recursos informacionais e Comunicação pública.

Também é possível observar contribuições discretas das disciplinas da área para o estudo dos aspectos que compõem as categorias Infraestrutura e recursos de recuperação e Coleta e armazenamento dos dados, demonstrando a importância das disciplinas com apelo tecnológico. Ressalta-se que, segundo os dados levantados por esta pesquisa, aspectos relacionados com as categorias Iniciativas e políticas de publicação de dados e Privacidade no acesso são os menos atendidos pelas disciplinas que compõem a estrutura curricular dos cursos de graduação com enfoque na Ciência da Informação no Brasil. 

contribuições no estudo do compartilhamento de dados governamentais na internet

Fábio Mosso Moreira, Marta Lígia Pomim Valentim e Ricardo César Gonçalves Sant'Ana

Figura 2 - Contribuições (em carga horária) das disciplinas que compõem a estrutura curricular dos três cursos de graduação com ênfase em Ciência da Informação analisados

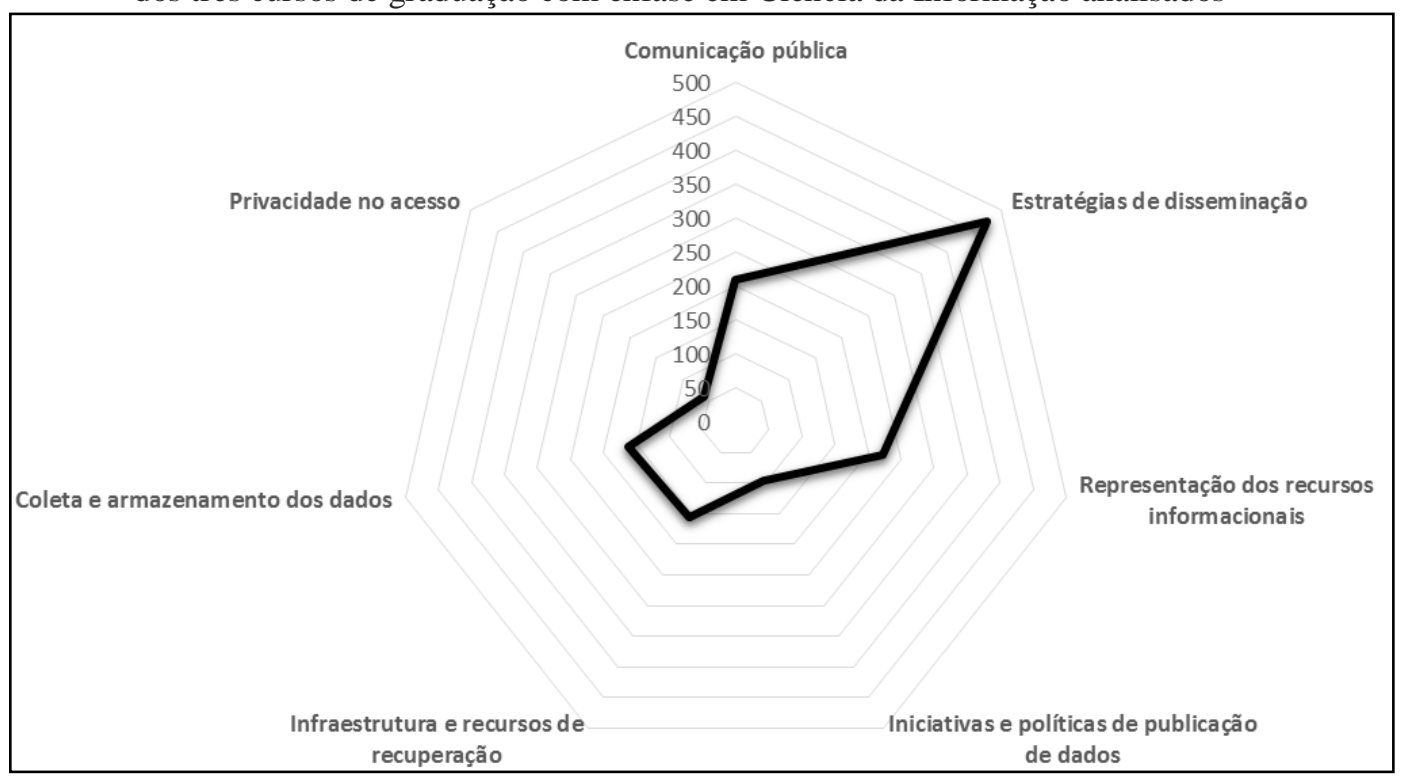

Fonte: Dados da pesquisa.

Para demonstrar a rede de intersecções interdisciplinares da Ciência da Informação, para os estudos do compartilhamento de dados governamentais na internet, elaborou-se um grafo (Figura 3) tomando como base a área de formação dos docentes responsáveis pelas disciplinas que podem contribuir com cada categoria (ilustrada pelos círculos laranjas) definida para representar este fluxo informacional, sendo verificados treze áreas do conhecimento, além da própria Ciência da Informação. Também, é possível observar a cardinalidade das relações interdisciplinares da rede (espessura das linhas), definida pela quantidade de professores com formações em determinada área do conhecimento, com destaque para uma forte relação entre a categoria Estratégias de disseminação com a área de Engenharias (ex: cardinalidade 7).

No grafo é possível observar que as categorias que se aproximam mais ao domínio tecnológico e de tratamento do conteúdo informacional, como Infraestrutura e recursos de recuperação, Coleta e armazenamento dos dados e Representação dos recursos informacionais, recebem contribuições interdisciplinares de áreas relacionadas às Ciências Exatas (ex: Ciência da Computação, Física, CSAI, Tecnologia em Processamento de Dados), representadas no grafo pelos quadrados azuis. Enquanto as categorias que são 

contribuições no estudo do compartilhamento de dados governamentais na internet

Fábio Mosso Moreira, Marta Lígia Pomim Valentim e Ricardo César Gonçalves Sant'Ana

mais associadas aos aspectos relacionados ao domínio da gestão pública e da atividade comunicacional, como Comunicação Pública, Estratégias de disseminação, Iniciativas e Políticas de publicação e Privacidade no acesso, recebem maiores contribuições das Ciências Humanas (ex: Biblioteconomia, Educação, Letras, Psicologia, Política Cientifica e Tecnológica, Sociologia Política, e Comparative American Studies), representadas no grafo pelo triangulo vermelho.

Figura 3 - Manifestação da interdisciplinaridade da Ciência da Informação por meio da formação dos docentes responsáveis pelas disciplinas que podem contribuir com o estudo dos aspectos envolvidos no compartilhamento de dados governamentais na Internet

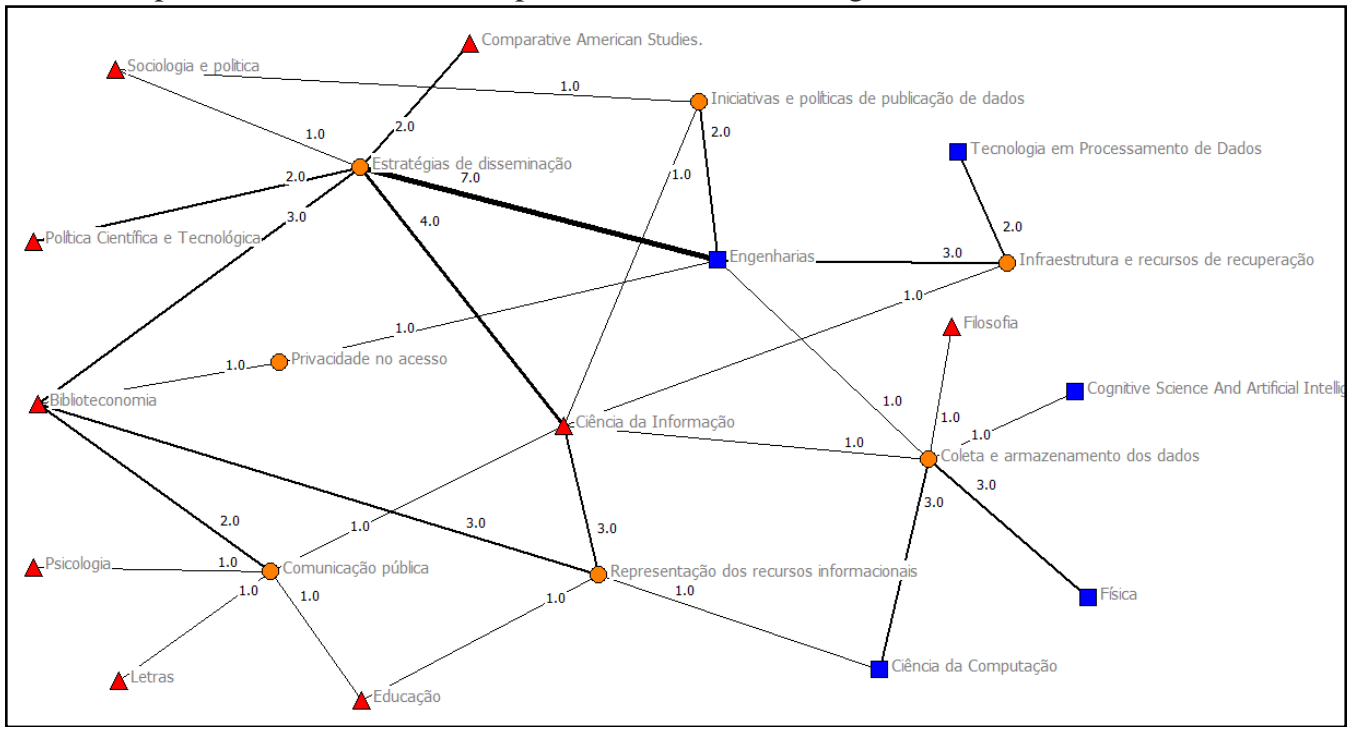

Fonte: Dados da pesquisa.

A rede ainda demonstra o destaque das Engenharias como área que atua de maneira interdisciplinar em cinco das sete categorias definidas para representar o compartilhamento de dados governamentais na internet.

\section{Considerações finais}

A pesquisa destacou áreas do conhecimento que apresentam interação interdisciplinar com a Ciência da Informação, evidenciando quais delas podem contribuir com o estudo dos aspectos envolvidos no processo de compartilhamento de dados governamentais na internet. Com base na literatura, Moreira, Valentim e Sant'Ana (2016) destacam as contribuições da 

contribuições no estudo do compartilhamento de dados governamentais na internet

Fábio Mosso Moreira, Marta Lígia Pomim Valentim e Ricardo César Gonçalves Sant'Ana

Comunicação, Ciência Política, Biblioteconomia, Arquivologia, Administração, Ciência da Computação, Direito e Estatística para este contexto.

A pesquisa aprofundou a temática enfocando as disciplinas que compõem a estrutura curricular dos cursos de graduação no Brasil, com enfoque na Ciência da Informação para o estudo desse fluxo informacional, verificandose vinte e três disciplinas, entre os três cursos analisados, que podem contribuir, efetivamente, para os estudos de aspectos envolvidos ao compartilhamento de dados governamentais na internet.

Entendendo que a interdisciplinaridade na Ciência da Informação manifesta-se, também, por meio da formação dos docentes da área, foram analisadas as formações dos docentes responsáveis pelas disciplinas associadas ao estudo desse fluxo informacional, constatando relações interdisciplinares com áreas como: Engenharias, Letras, Biblioteconomia, Psicologia, Educação, Sociologia e política, Comparative American Studies, Política Científica e Tecnológica, Ciência da Computação, Tecnologia em Processamento de Dados, Física, (CSAI) e Filosofia.

\section{Referências}

ANDERSEN, K. V.; HENRIKISEN, H. Z. E-Government Maturity Models: Extension of the Layne and Lee Model. Government Information Quarterly, Oxford, v. 23, n. 1, p. 236-248, 2006.

BARDIN, L. Análise de conteúdo. Lisboa: Edições 70, 2009.

BICALHO, L. M.; OLIVEIRA, M. Aspectos conceituais da multidisciplinaridade e da interdisciplinaridade e a pesquisa em Ciência da Informação. Encontros Bibli: revista eletrônica de Biblioteconomia e Ciência da Informação, Florianópolis, v. 16, n. 32, p. 1-26, 2011.

BORKO, H. Information Science: What is it? American Documentation, Washington, v. 19, n. 1, p. 3-5, Jan. 1968.

BRASIL. Conselho Nacional de Desenvolvimento Científico e Tecnológico. Plataforma Lattes. Brasília, [20--]. 

contribuições no estudo do compartilhamento de dados governamentais na internet

Fábio Mosso Moreira, Marta Lígia Pomim Valentim e Ricardo César Gonçalves Sant'Ana

BRASIL. Lei $\mathrm{n}^{\circ} 12.527$, de 18 de novembro de 2011. Regula o acesso a informações previsto no Inciso XXXIII do Art. $5^{\circ}$, no Inciso II do $\S 3^{\circ}$ do Art. 37 e no $\S 2^{\circ}$ do Art. 216 da Constituição Federal; altera a Lei n ${ }^{\circ} 8.112$, de 11 de dezembro de 1990; revoga a Lei ${ }^{\circ} 11.111$, de 5 de maio de 2005, e dispositivos da Lei n ${ }^{\circ} 8.159$, de 8 de janeiro de 1991; e dá outras providências. Diário Oficial [da] República Federativa do Brasil, Brasília, 18 nov. 2011. Edição extra.

CARVALHO, K. Disseminação da informação e informação de inteligência organizacional. DataGramaZero, Rio de Janeiro, v. 2, n. 3, p. 1-9, jun. 2001.

DAVIS JÚNIOR, C. A.; SOUZA, L. A.; BORGES, K. A. V. Disseminação de dados geográficos na Internet. In: CASANOVA, M. A. et al. (Org.) Banco de Dados Geográficos. Curitiba: EspaçoGeo, 2005. p. 353-378.

LARA, M. L. G.; CONTI, V. L. Disseminação da informação e usuários. São Paulo em Perspectiva, São Paulo, v. 17, n. 3-4, p. 26-34, 2003.

MEDJAHED, B. et al. Infrastructure for E-Government web services. IEEE Computer Society, Washington, v. 7, n. 1, p. 58-65, Jan./Feb. 2003.

MOREIRA, F. M.; VALENTIM, M. L. P.; SANT'ANA, R. C. G. Interdisciplinaridades em Ciência da Informação: um estudo do compartilhamento de dados governamentais na Web. In: ENCONTRO INTERNACIONAL DADOS, INFORMAÇÃO E TECNOLOGIA, 3., 2016, Marília, SP, 2016. Anais... Marília: Programa de Pós-Graduação em Ciência da Informação, 2016. Doc. não paginado.

MORIN, E.; LE MOIGNE, J. A inteligência da complexidade. 3. ed. Uberaba: Peirópolis, 2000. 268 p.

PINHEIRO, L. V. R. Processo evolutivo e tendências contemporâneas da Ciência da Informação. Informação \& Sociedade: Estudos, João Pessoa, v. 15, n. 1, p. 13-48, jan./jun. 2005.

PINHEIRO, L. V. R. Ciência da Informação: desdobramentos disciplinares, interdisciplinaridade e transdisciplinaridade. In: GONZÁLEZ DE GÓMEZ, M. N.; ORRICO, E. G. D. (Org.). Políticas de memória e informação: reflexos na organização do conhecimento. Natal: EDUFRN, 2006. p. 111-141.

PLATT NETO, O. A. P.; CRUZ, F.; VIERA, A. L. Transparência das contas públicas: um enfoque no uso da Internet como instrumento de publicidade na UFSC. Revista Contemporânea de Contabilidade, Florianópolis, v. 1, n. 5, p. 135-146, jan./jun. 2006.

POMBO, O. Interdisciplinaridade: ambições e limites. Lisboa: Relógio D’Água, 2004. 

contribuições no estudo do compartilhamento de dados governamentais na internet

Fábio Mosso Moreira, Marta Lígia Pomim Valentim e Ricardo César Gonçalves Sant'Ana

ROBINSON, D. et al. Government data and the invisible hand. Yale Journal of Law and Technology, Yale, v. 12, n. 1, p. 157-175, 2009.

RODRIGUES, F. A.; SANTANA, R. C. G. Restrições tecnológicas e de acesso a dados disponíveis sobre destino de repasse financeiros federais para a saúde pública em ambientes informacionais digitais. In: ENANCIB, 13., 2012, Rio de Janeiro. Anais... Rio de Janeiro: ANCIB, 2012. Doc. não paginado.

SANT'ANA, R. C. G.; RODRIGUES, F. A. Uso de modelos de dados multidimensionais para a ampliação da transparência ativa. Liinc em Revista, Rio de Janeiro, v. 9, n. 2, p. 469-487, nov. 2013.

SANT'ANA, R. C. G. Tecnologia e gestão pública municipal: mensuração da interação com a sociedade. São Paulo: Cultura Acadêmica, 2009. 181 p.

SANTANA, R. C. G.; RODRIGUES, F. A. Visualização de afinidades entre parlamentares mediante dados de votações no Senado Brasileiro. Informação \& Sociedade: Estudos, João Pessoa, v. 23, n. 1, p. 49-59, 2013.

SANTOS, L. M. L.; PELOSI, E. M.; OLIVEIRA, B. C. S. C. M. de. Teoria da Complexidade e as múltiplas abordagens para compreender a realidade social. Serviço Social em Revista, Londrina, v. 14, n. 2, p. 47-72, jan./jun. 2012.

SANTOS, P. L. A. C.; SANT'ANA, R. C. G. Transferência da informação: análise para valoração de unidades de conhecimento. DataGramaZero, Rio de Janeiro, v. 3, n. 2, 16 p., abr. 2002.

SANTOS, P. L. A. C.; SANT'ANA, R. C. G. Dado e granularidade na perspectiva da informação e tecnologia: uma interpretação pela ciência da informação. Ciência da Informação, Brasília, v. 42, n. 2, p.199-209, maio/ago, 2013.

SARACEVIC, T. Interdisciplinary nature of Information Science. Ciência da Informação, Brasília, v. 24, n. 1, p. 1-9, 1995.

THE ANNOTATED 8 Principles of Open Government Data. [2014].

UCINET Software. Version 6.531. 2014.

UNIVERSIDADE FEDERAL DE SANTA CATARINA. Planos de ensino 2017-1. Florianópolis: Departamento da Ciência da Informação, 2017.

UNIVERSIDADE FEDERAL DE SÃO CARLOS. Curso de Biblioteconomia e Ciência da Informação. Ementas e objetivos das disciplinas obrigatórias. São Carlos, [20--].

UNIVERSIDADE FEDERAL DE SÃO CARLOS. Curso de Biblioteconomia e Ciência da Informação. Horário 2017/2. São Carlos, SP, [2017]. 
UNIVERSIDADE DE SÃO PAULO. Grade curricular. São Paulo:

Superintendência de Tecnologia da Informação/USP, [20--].

VAZ, J. C.; RIBEIRO, M. M.; MATHEUS, R. Dados Governamentais Abertos e seus impactos sobre os conceitos e práticas de transparência no Brasil.

Cadernos PPG-AU/FAUFBA, Salvador, v. 9, n. 1, p. 45-62, 2010.

\title{
Interdisciplinarity of Information Science and its contributions in the study of government data sharing on the internet
}

\begin{abstract}
The internet can be considered an important alternative to enable greater interaction between public administration and society, and one of the actions refers to the sharing of governmental databases. This information flow involves specific questions that are studied in Information Science, which presents an interdisciplinary characteristic due to the complexity of its object, the use of theories and methodologies from other areas and the diversity of its scientific body. The objective of this research was to identify the fields of knowledge that present an interdisciplinary interaction with Information Science, to highlight which of them can contribute to the study of the sharing of governmental data on the internet, and to relate disciplines of the area with the analysis of the aspects present in this informational flow. The Content Analysis method was applied, based on data collection at the official portals of the University of São Paulo, Ribeirao Preto campus, Federal University of São Carlos and Federal University of Santa Catarina, in order to identify the curricular structure of undergraduate courses with focus on the Information Science area in Brazil and analyze their teaching plans. The results indicate which areas of knowledge are interdisciplinary to Information Science and which ones can contribute to the study of the aspects involved in the process of sharing government data on the internet. In addition, it also highlights which disciplines make up the structure of undergraduate courses analyzed and that can effectively contribute to the study of this information flow.
\end{abstract}

Keywords: Interdisciplinary. Information science. Data sharing. Government data. Information flows.

Recebido: 28/07/2017

Aceito: $13 / 11 / 2017$ 